\title{
Late, Rare, and Asymptomatic Bladder Metastasis of Breast Carcinoma: A Case Report
}

\author{
Murat Öztürk , (i) Serdar Aykan², (i) Nizamaddin Koca ${ }^{3}$, () Soner Çoban ${ }^{1}$, (i) Gül Ayşen Öztürk ${ }^{4}$, \\ Muhammet Güzelsoy ${ }^{1}$, Ali Rıza Türkoğlu1 \\ ${ }^{1}$ Department of Urology, University of Health Sciences, Bursa Yuksek Ihtisas Training and Research Hospital, Bursa, Turkey \\ ${ }^{2}$ Department of Urology, University of Health Sciences, Haydarpasa Numune Training and Research Hospital, Istanbul, Turkey \\ ${ }^{3}$ Department of Internal Medicine, University of Health Sciences, Bursa Yuksek Ihtisas Training and Research Hospital, Bursa, Turkey \\ ${ }^{4}$ Department of Radiation Oncology, Bursa Ali Osman Sonmez Oncology Hospital, Bursa, Turkey
}

\begin{abstract}
Breast carcinoma is the most common cancer after non-melanoma skin cancers. It often metastasizes to the lungs, lymph nodes, and liver and rarely spreads to the bladder. Bladder cancer usually manifests with painless clotted macroscopic hematuria. Although there are no organ-specific symptoms, in case of a malignancy, all organs must be checked for metastasis for the whole lifetime. In this case, we present a patient with late onset asymptomatic bladder metastasis with different primary tumors in each breast. Keywords: Bladder cancer; bladder metastasis; breast cancer; metastasis.
\end{abstract}

$B^{r a s e n}$ reast cancer is the most common invasive cancer after non-melanoma skin cancers. In breast cancer, the patient usually dies because of metastasis of the primary tumor ${ }^{[1,2]}$. Breast cancers usually spread to the lungs, bone, lymph nodes, liver, pleura, adrenal gland, and skin. In the literature, there are few cases that report breast cancers that spread to the bladder ${ }^{[3,4]}$. Breast cancer represents the primary site in approximately $2.5 \%$ cases of all metastatic bladder cancer cases ${ }^{[5]}$. This case report presents incidentally-detected bladder metastasis of invasive ductal carcinoma in a patient with different histopathological types of cancer in each breast, which is extremely rare.

\section{Case Report}

A thirty-eight-year-old woman was admitted to the outpatient clinic with a mass in her bladder, which was detected during routine examination without any complaint. A $35 \times 9-\mathrm{mm}$ mass was observed in the base and left sidewalls of the bladder in the computerized tomographic image (Fig. 1).

She had left modified radical mastectomy (MRM) with axillary dissection (AD) due to invasive ductal carcinoma in February 2009. Histopathological staining for estrogen receptor (ER), progesterone receptor (PR), and c-erb-B2 was $(+),(+)$ and $(+++)$, respectively. She had bone metastasis at

Correspondence (iletişim): Serdar Aykan, M.D. Saglik Bilimleri Universitesi Haydarpasa Numune Egitim ve Arastirma Hastanesi Uroloji Klinigi, Istanbul, Turkey

Phone (Telefon): +90 5558212140 E-mail (E-posta): drserdaraykan@hotmail.com

Submitted Date (Başvuru Tarihi): 24.07.2018 Accepted Date (Kabul Tarihi): 04.09.2018

Copyright 2019 Haydarpaşa Numune Medical Journal

OPEN ACCESS This is an open access article under the CC BY-NC license (http://creativecommons.org/licenses/by-nc/4.0/). 
the time of diagnosis, which was staged as T2N3M1. Paclitaxel, Herceptin, tamoxifen, leuprolide acetate, and palliative radiotherapy with zoledronic acid were given as firstline therapy. The treatment was changed to lapatinib and capecitabine because of bone metastasis progression.

Right MRM with AD was performed in 2013 because of invasive lobular carcinoma detected in June 2013, which was staged as T2N2M0. ER, PR, and c-erb-B2 were negative. Doxorubicin-cyclophosphamide and paclitaxel therapy was administered to the patient. Cystoscopy was performed for an asymptomatic bladder mass observed using computed tomography performed during routine

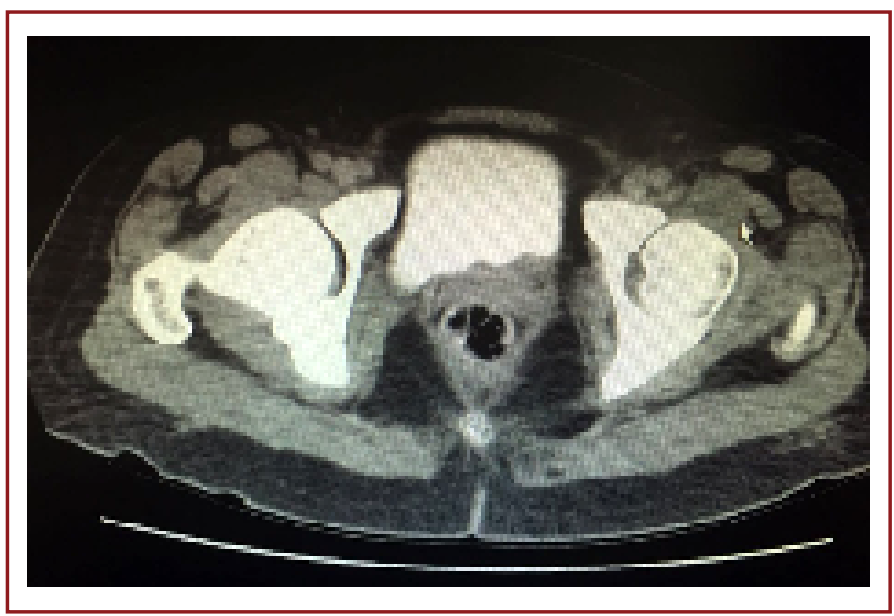

Figure 1. CT image shows a $35 \times 9 \mathrm{~mm}$ mass in the base and left sidewalls of the bladder.

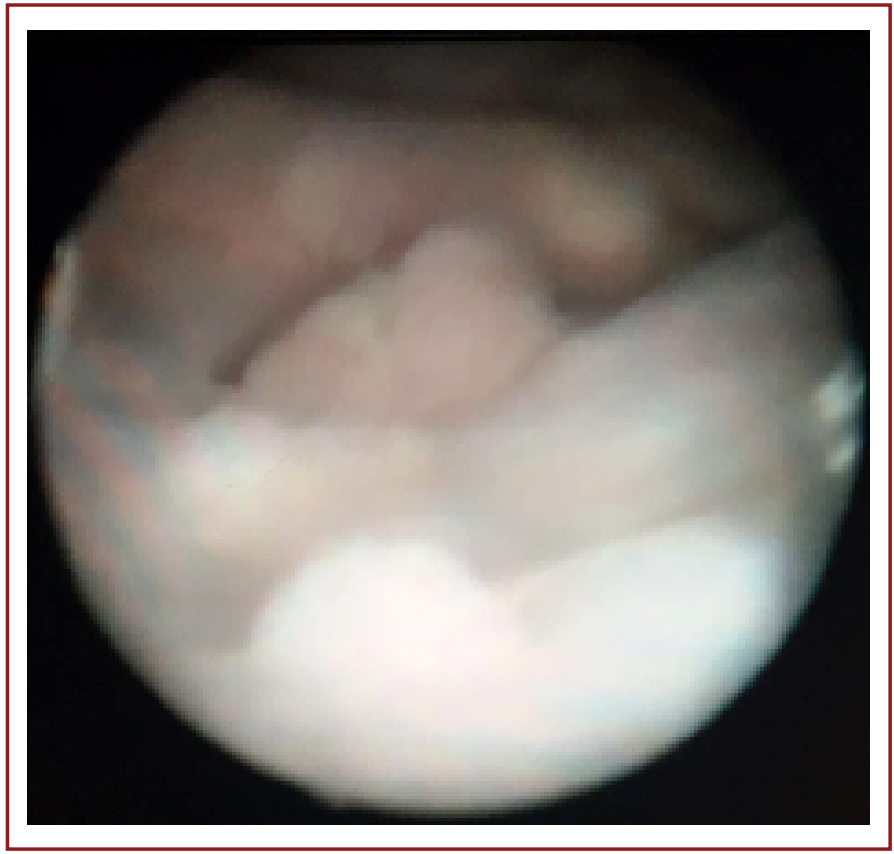

Figure 2. Polypoid tissue mass with the inflammatory changes in the left wall of the bladder base was observed. examinations in June 2015. A polypoid tissue mass with inflammatory changes was observed in the left wall of the bladder base (Fig. 2). Widespread polypoid mass was resected, and no further tumor formation was observed in the bladder.

Histopathological examination of cross-sections showed ulceration forming urothelial infiltration in the tumor tissue. The tumor comprised atypical pleomorphic cells showing cords and irregular glands arranged in fibro-myxoid stroma (Figs. 3, 4). Tumor cells showed mammaglobin (Fig. 5), GATA3 (Fig. 6), c-erb-B2, and e-cadherin immunoreactivity and stained positive for ER, PR, and GCDFP15. The patient was diagnosed with ductal adenocarcinoma metastases with histopathological and immunohistochemical findings.

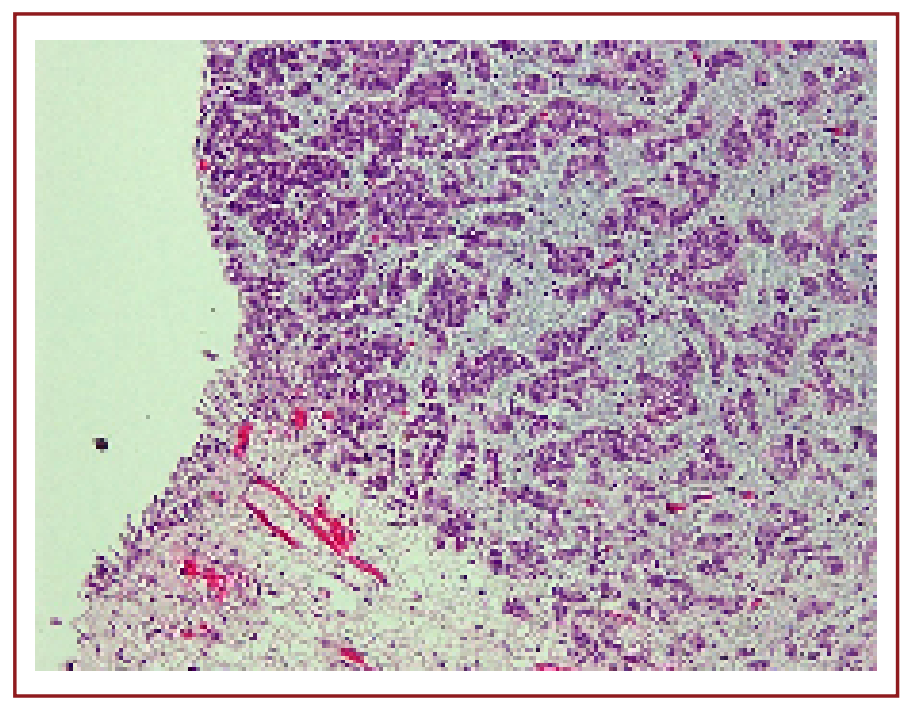

Figure 3. Urothelial epithelium infiltrated with the tumor (H\&E x100).

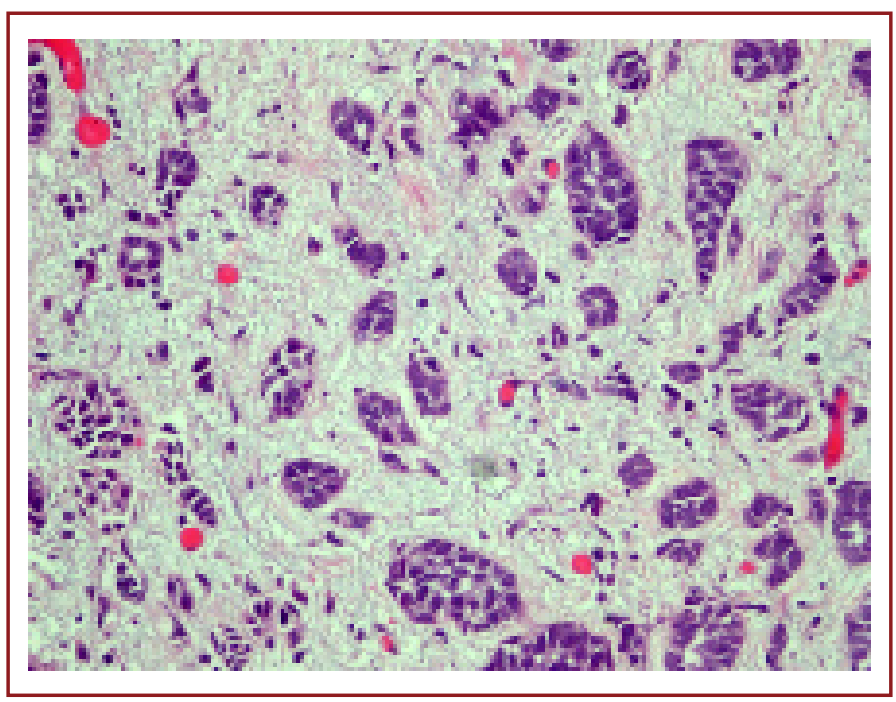

Figure 4. Urothelial epithelium infiltrated with the tumor (H\&E x200). 


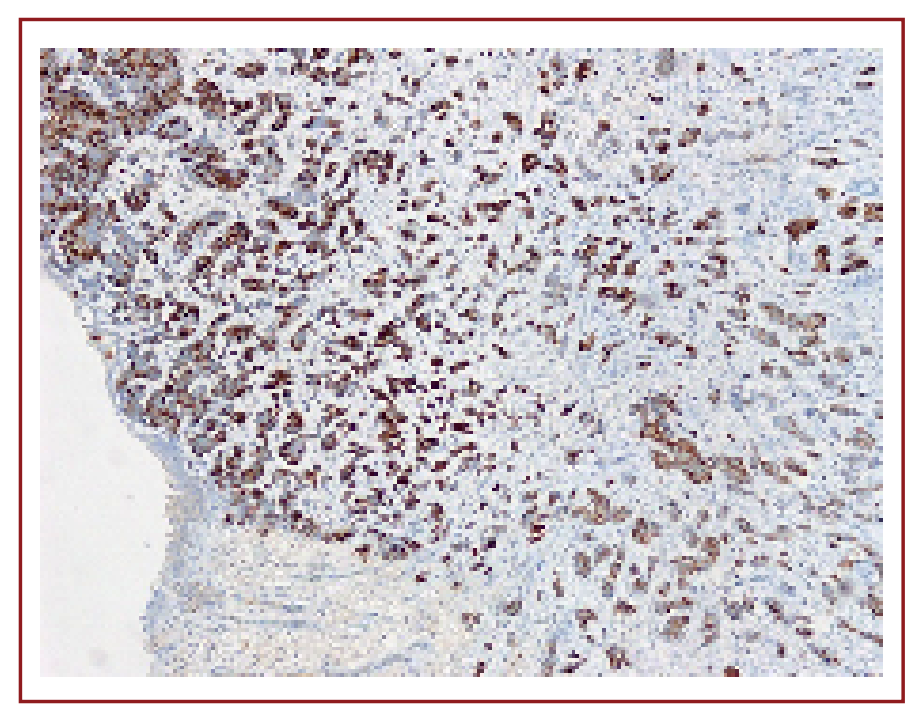

Figure 5. Tumor cells show mammaglobin immunoreactivity.

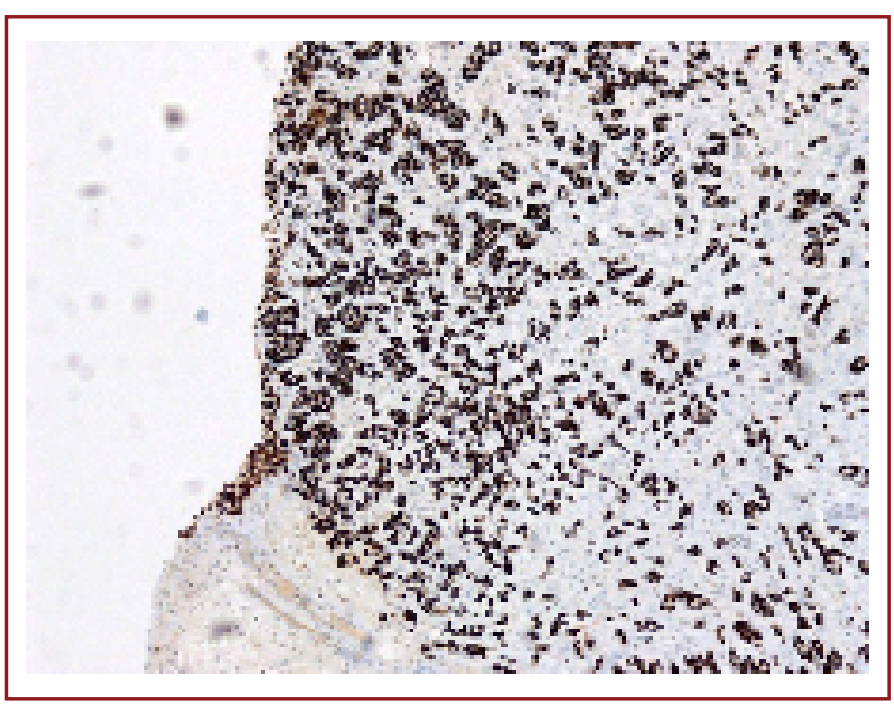

Figure 6.Tumor cells show GATA3 immunoreactivity.

\section{Discussion}

Secondary bladder tumors are rare, constituting approximately $2 \%$ of all bladder malignancies ${ }^{[3]}$. The majority of metastatic tumors originate as a result of direct invasion of prostate, colon, and cervical cancer. Less frequently, leukemia and lymphoma metastases cause secondary bladder metastases. Breast, lung, and skin tumors rarely metastasize to the bladder ${ }^{[6]}$.

The diagnosis of metastases is performed using cystoscopy and bladder biopsy. Macroscopically, bladder metastasis is seen as a mass, irregular lesion, mucosal nodules, and abnormal mucosal thickening. In our case, a mass was observed during $\mathrm{CT}$ imaging and trans-ureteral resection was performed.
Symptomatic bladder metastasis is observed during the late stages of breast cancer. Bates and Baithun ${ }^{[5]}$ reported 7 cases of primary breast cancer metastasis ( 6 of which had metastasized widely) in 282 cases of secondary urinary bladder metastases in a series of 6289 postmortem bladder tumor analysis. The most common symptoms are lower urinary tract symptoms, flank/abdominal pain, hydronephrosis, and painless hematuria ${ }^{[2]}$. It may also occur as recurrent urinary tract infections and urinary incontinence. Hematuria may not only be related with bladder metastasis but may also be a side effect of cyclophosphamide, which is used for the treatment of primary breast tumor. Our patient had no symptoms.

Metastasis to the bladder indicates a poorer prognosis compared with bone metastases in breast cancer ${ }^{[7]}$. In our patient, bone metastasis was observed at the time of diagnosis of invasive ductal cancer and bladder metastasis was detected 6 years after the initial diagnosis. Although invasive ductal cancer is more common than lobular cancer, infiltrative lobular carcinoma metastasizes more to the bladder ${ }^{[8]}$. However, our patient's bladder metastasis originated from invasive ductal carcinoma.

$E R, P R$, and c-erb-B2 are the three main receptors seen in breast carcinoma. These receptors were investigated in bladder metastasis of primary breast carcinoma ${ }^{[9]}$. The life span is adversely affected in the event of a negative presence of these receptors in the bladder despite being positive in the breast alone ${ }^{[9,10]}$. In the breast, ER- and PRpositive tumors respond better to hormone therapy ${ }^{[10]}$. It has been reported that c-erb-B2 positive breast tumors are more aggressive.

Although all three receptors were positive in our patient's first primary breast carcinoma-invasive ductal carcinomaand negative in her second primary breast carcinoma-invasive lobular carcinoma-all except c-erb-B2 were positive in bladder metastasis.

The most important feature in our case is bladder metastasis without any symptoms, which is rare in the literature: one patient with two different primary breast tumors.

Surgery, chemotherapy, radiotherapy, hormonal therapy, or combinations thereof are used in the treatment of metastatic bladder. Our patient, who is still alive, received gemcitabine, Herceptin, and zoledronic acid treatment for bladder metastasis.

\section{Conclusions}

Late and asymptomatic bladder metastasis of breast carcinoma is rare. Each organ must be evaluated for metastasis 
in case of the presence of a primary tumor. Follow-up of the tumor should be performed for the entire lifetime. Routine tumor follow-up provides patients with an opportunity to have longer disease-free survival, as in our patient, who is still alive and healthy.

Informed Consent: Written informed consent was obtained from the patient for the publication of the case report and the accompanying images.

Peer-review: Externally peer-reviewed.

Conflict of Interest: None declared.

Authorship Contributions: Concept: M.O., S.A., A.R.T.; Design: M.O., S.A., N.K., S.C., M.G.; Data Collection or Processing: M.O., S.A., N.K., S.C., G.A.O., M.G., A.R.T.; Analysis or Interpretation: M.O., S.A., G.A.O.; Literature Search: N.K., S.C., G.A.O., M.G.; Writing: M.O., S.A., A.R.T.

Financial Disclosure: The authors declared that this study received no financial support.

\section{References}

1. Vulcano E, Montesano M, Battista C, Carino R, Perrone G, Vincenzi $B$, et al. Urinary complications from breast cancer metastasis: case report and review of the literature. G Chir 2010;31:243-5.

2. Luczyńska E, Pawlik T, Chwalibóg A, Anioł J, Ryś J. Metastatic
Breast Cancer to the Bladder case report and review of literature. J Radiol Case Rep 2010;4:19-26. [CrossRef]

3. Shah KG, Modi PR, Rizvi J. Breast carcinoma metastasizing to the urinary bladder and retroperitoneum presenting as acute renal failure. Indian J Urol 2011;27:135-6. [CrossRef]

4. Viadana E, Bross ID, Pickren JW. An autopsy study of some routes of dissemination of cancer of the breast. Br J Cancer 1973;27:336-40. [CrossRef]

5. Bates AW, Baithun SI. Secondary neoplasms of the bladder are histological mimics of nontransitional cell primary tumours: clinicopathological and histological features of 282 cases. Histopathology 2000;36:32-40. [CrossRef]

6. Modh RA, Corbyons KA, Yeung LL. A rare metastasis to the bladder. Case Rep Urol 2013;2013:789039. [CrossRef]

7. Lawrentschuk N, Chan Y, Bolton DM. Metastatic breast cancer to the bladder. Breast J 2005;11:143. [CrossRef]

8. Feldman PA, Madeb R, Naroditsky I, Halachmi S, Nativ O. Metastatic breast cancer to the bladder: a diagnostic challenge and review of the literature. Urology 2002;59:138. [CrossRef]

9. Iguchi C, Nio Y, Itakura M. Heterogeneic expression of estrogen receptor between the primary tumor and the corresponding involved lymph nodes in patients with node-positive breast cancer and its implications in patient outcome. J Surg Oncol 2003;83:85-93. [CrossRef]

10. Lin WC, Chen JH. Urinary bladder metastasis from breast cancer with heterogeneic expression of estrogen and progesterone receptors. J Clin Oncol 2007;25:4308-10. [CrossRef] 